NASA/TM-2013-216523

\title{
Optical Strain and Crack-Detection Measurements on a Rotating Disk
}

Mark Woike

Glenn Research Center, Cleveland, Ohio

Ali Abdul-Aziz

Cleveland State University, Cleveland, Ohio

Michelle Clem and Gustave Fralick

Glenn Research Center, Cleveland, Ohio 


\section{NASA STI Program . . . in Profile}

Since its founding, NASA has been dedicated to the advancement of aeronautics and space science. The NASA Scientific and Technical Information (STI) program plays a key part in helping NASA maintain this important role.

The NASA STI Program operates under the auspices of the Agency Chief Information Officer. It collects, organizes, provides for archiving, and disseminates NASA's STI. The NASA STI program provides access to the NASA Aeronautics and Space Database and its public interface, the NASA Technical Reports Server, thus providing one of the largest collections of aeronautical and space science STI in the world. Results are published in both non-NASA channels and by NASA in the NASA STI Report Series, which includes the following report types:

- TECHNICAL PUBLICATION. Reports of completed research or a major significant phase of research that present the results of NASA programs and include extensive data or theoretical analysis. Includes compilations of significant scientific and technical data and information deemed to be of continuing reference value. NASA counterpart of peer-reviewed formal professional papers but has less stringent limitations on manuscript length and extent of graphic presentations.

- TECHNICAL MEMORANDUM. Scientific and technical findings that are preliminary or of specialized interest, e.g., quick release reports, working papers, and bibliographies that contain minimal annotation. Does not contain extensive analysis.

- CONTRACTOR REPORT. Scientific and technical findings by NASA-sponsored contractors and grantees.
- CONFERENCE PUBLICATION. Collected papers from scientific and technical conferences, symposia, seminars, or other meetings sponsored or cosponsored by NASA.

- SPECIAL PUBLICATION. Scientific, technical, or historical information from NASA programs, projects, and missions, often concerned with subjects having substantial public interest.

- TECHNICAL TRANSLATION. Englishlanguage translations of foreign scientific and technical material pertinent to NASA's mission.

Specialized services also include creating custom thesauri, building customized databases, organizing and publishing research results.

For more information about the NASA STI program, see the following:

- Access the NASA STI program home page at http://www.sti.nasa.gov

- E-mail your question to help@sti.nasa.gov

- Fax your question to the NASA STI Information Desk at 443-757-5803

- Phone the NASA STI Information Desk at 443-757-5802

- Write to: STI Information Desk NASA Center for AeroSpace Information 7115 Standard Drive Hanover, MD 21076-1320 
NASA/TM-2013-216523

SPIE 8693-23

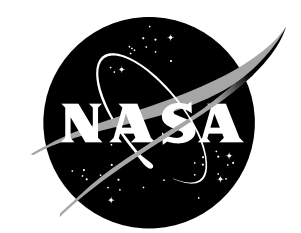

\section{Optical Strain and Crack-Detection Measurements on a Rotating Disk}

Mark Woike

Glenn Research Center, Cleveland, Ohio

Ali Abdul-Aziz

Cleveland State University, Cleveland, Ohio

Michelle Clem and Gustave Fralick

Glenn Research Center, Cleveland, Ohio

Prepared for the

Smart Structures and Materials and Nondestructive Evaluation and Health Monitoring 2013 sponsored by the International Society for Optical Engineering (SPIE)

San Diego, California, March 10-14, 2013

National Aeronautics and

Space Administration

Glenn Research Center

Cleveland, Ohio 44135 
This report contains preliminary findings, subject to revision as analysis proceeds.

Trade names and trademarks are used in this report for identification only. Their usage does not constitute an official endorsement, either expressed or implied, by the National Aeronautics and Space Administration.

Level of Review: This material has been technically reviewed by technical management.

Available from

NASA Center for Aerospace Information 7115 Standard Drive

Hanover, MD 21076-1320
National Technical Information Service 5301 Shawnee Road Alexandria, VA 22312

Available electronically at http://www.sti.nasa.gov 


\title{
Optical Strain and Crack-Detection Measurements on a Rotating Disk
}

\author{
Mark Woike \\ National Aeronautics and Space Administration \\ Glenn Research Center \\ Cleveland, Ohio 44135 \\ Ali Abdul-Aziz \\ Cleveland State University \\ Cleveland, Ohio 44115 \\ Michelle Clem and Gustave Fralick \\ National Aeronautics and Space Administration \\ Glenn Research Center \\ Cleveland, Ohio 44135
}

\begin{abstract}
The development of techniques for the in-situ measurement and structural health monitoring of the rotating components in gas turbine engines is of major interest to NASA. As part of this on-going effort, several experiments have been undertaken to develop methods for detecting cracks and measuring strain on rotating turbine engine like disks. Previous methods investigated have included the use of blade tip clearance sensors to detect the presence of cracks by monitoring the change in measured blade tip clearance and analyzing the combined disk-rotor system's vibration response. More recently, an experiment utilizing a novel optical Moiré based concept has been conducted on a subscale turbine engine disk to demonstrate a potential strain measurement and crack detection technique. Moiré patterns result from the overlap of two repetitive patterns with slightly different spacing. When this technique is applied to a rotating disk, it has the potential to allow for the detection of very small changes in spacing and radial growth in a rotating disk due to a flaw such as a crack. This investigation was a continuation of previous efforts undertaken in 2011 to 2012 to validate this optical concept. The initial demonstration attempted on a subscale turbine engine disk was inconclusive due to the minimal radial growth experienced by the disk during operation. For the present experiment a new subscale Aluminum disk was fabricated and improvements were made to the experimental setup to better demonstrate the technique. A circular reference pattern was laser etched onto a subscale engine disk and the disk was operated at speeds up to $12000 \mathrm{rpm}$ as a means of optically monitoring the Moiré created by the shift in patterns created by the radial growth due the presence of the simulated crack. Testing was first accomplished on a clean defect free disk as a means of acquiring baseline reference data. A notch was then machined in to the disk to simulate a crack and testing was repeated for the purposes of demonstrating the concept. Displacement data was acquired using external blade tip clearance and shaft displacement sensors as a means of confirming the optical data and for validating other sensor based crack detection techniques.
\end{abstract}

\section{Introduction}

The development of in-situ measurement technologies and fault-detection techniques for the structural health monitoring of gas turbine engines is of high interest to NASA's Aviation Safety and Fundamental Aeronautics Programs. The rotating components of modern gas turbine engines operate in severe environmental conditions and are exposed to high thermal and mechanical loads. The cumulative effects of these loads can lead to high stresses, structural deformities, cracks, and eventual component failure. Current detection practices involve periodic inspections and schedule-based maintenance of 
engine components to ensure their integrity over the lifetime of the engine. However, these methods have their limitations, and failures are experienced leading to unscheduled maintenance and unplanned engine shutdowns. To prevent these failures and enhance aviation safety, the NASA Glenn Research Center has investigated several new techniques and sensor technologies for the in-situ structural health monitoring and detection of flaws in gas turbine engines.

Over the last several years research has been conducted in the NASA Glenn Research Center's Rotor Dynamics Laboratory to develop both global and local approaches for monitoring critical rotor components (Refs. 1 to 8). This paper will present data from a sensor based technique that was previously investigated along with the results of a recently conducted novel optical Moiré based strain measurement and crack detection experiment. The sensor based anomaly detection method involved introducing a notch on a simulated turbine engine disk and monitoring its vibration response as the disk was rotated at speeds up to $12000 \mathrm{rpm}$. The vibration response was characterized by using externally mounted capacitive blade tip clearance sensors to measure the combined disk-rotor system's whirl amplitude and phase during operation. Testing was performed on a clean undamaged baseline disk and a disk with a $50.8 \mathrm{~mm}(2 \mathrm{in}$.) long notch machined into the disk to simulate a crack. The responses were compared and evaluated against the theoretical models to investigate the applicability and success of detecting the notch.

The most recent investigation was to determine if an optical technique based on the Moiré principal could be used to measure localized radial growth and strain due to high stresses caused by an anomaly such as a crack in a rotating disk. The experiment involved laser etching a circular reference pattern on a subscale engine disk and introducing a $50.8 \mathrm{~mm}$ ( 2 in.) long notch machined into it to simulate a crack. The disk was operated at speeds up to $12000 \mathrm{rpm}$ and the Moiré pattern due to the shift with respect to the reference pattern was monitored as a means of detecting the localized radial growth of the disk due to the defect. In addition, displacement data sets were acquired using external blade tip clearance and shaft displacement sensors for comparison to the optical data and to further develop and validate other sensor based fault detection techniques.

\section{Vibration Based Crack Detection Technique}

This crack-detection methodology involved introducing a notch on a simulated turbine engine disk and monitoring its vibration response as the disk was rotated at speeds up to $12000 \mathrm{rpm}$. The vibration response was characterized by monitoring the disk-rotor system's whirl amplitude and phase during operation. The disk-rotor system's whirl amplitude and phase were derived from the blade tip clearance profile which was measured using externally mounted capacitive blade tip clearance sensors. The testing was performed on a clean undamaged baseline disk and a disk with a $50.8 \mathrm{~mm}(2 \mathrm{in}$.) long notch machined into the disk to simulate a crack. The responses were compared to each other and the theoretical model to determine whether this technique could detect the presence of the notch. A description of the High Precision Spin Rig, the baseline theory behind this technique, the experimental setup, and the results are presented in the following sections.

\section{High Precision Spin Rig Description}

Figure 1 shows the Rotordynamics Laboratory's High Precision Spin Rig, which can accommodate simulated engine rotor disks of up to $235 \mathrm{~mm}(9.25 \mathrm{in}$.) in diameter. It has a stainless steel shaft with a length of $781 \mathrm{~mm}$ (30.75 in.) and diameter of $20 \mathrm{~mm}$ (0.79 in.). The shaft is supported by precision contact ball bearings on each end and has adjustable dampers that were positioned along the length of the shaft for these experiments. An encoder mounted on the end of the shaft was used by the control system to provide closed-loop control of rig speed. A secondary optical tachometer was used to record the speed into the data system and to synchronize the data to the rig's rotation. A 12-hp custom-built, brushless direct-current (dc) motor was used to rotate the spin rig and the simulated engine disks at speeds up $12000 \mathrm{rpm}$. 


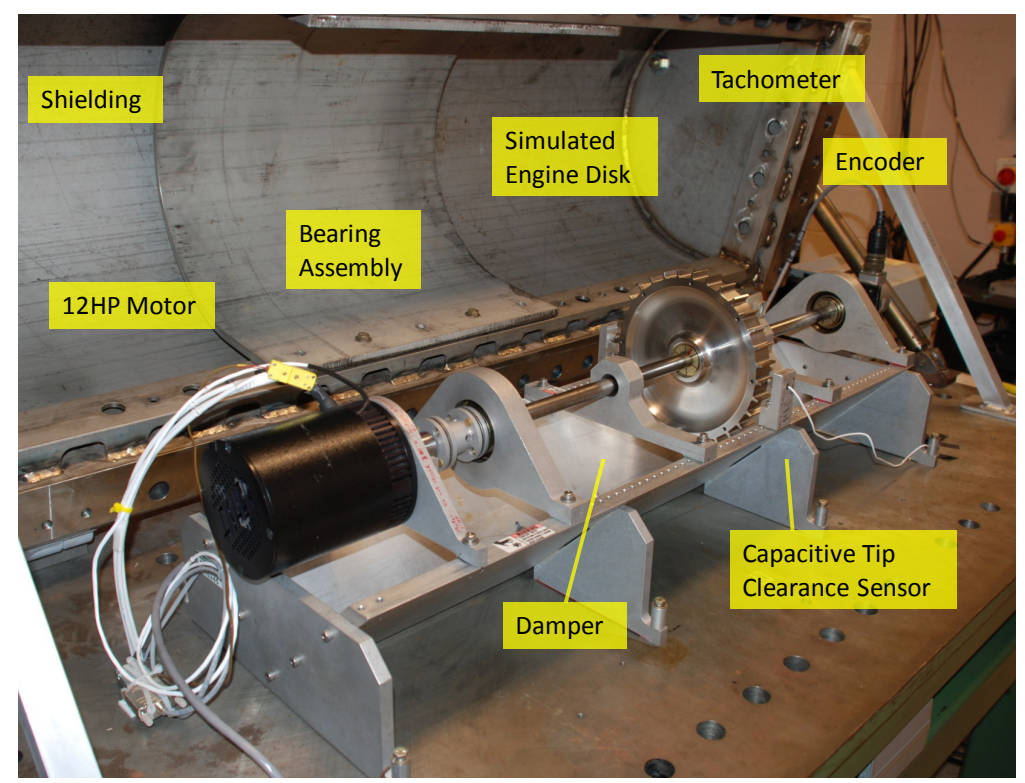

Figure 1.-High precision spin rig.

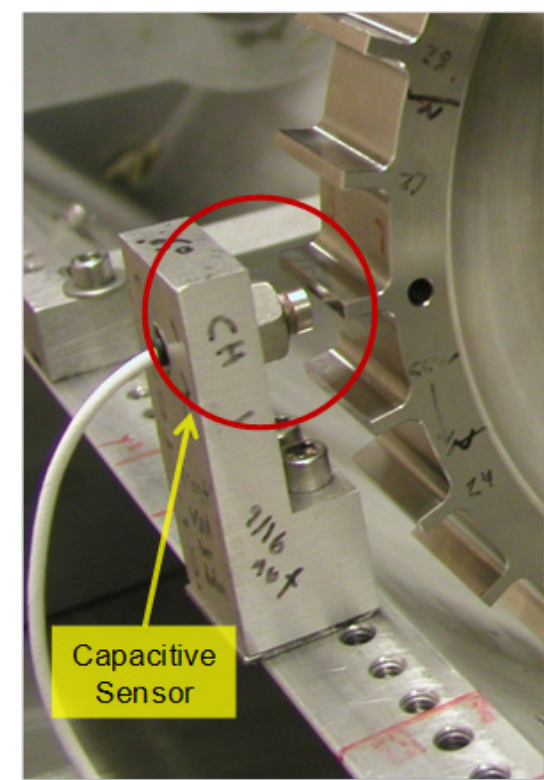

Figure 2.-Capacitive blade tip clearance probe.

The rig was set up to acquire two channels of radial blade-tip-clearance data from the simulated engine disk using capacitive displacement sensors (Fig. 2). Theses sensors were developed as part of a NASA Small Business Innovation Research (SBIR) contract and were different from traditional capacitive sensors in that their operation was based on a dc offset technique instead of the typical modulation technique (Ref. 8). A National Instruments System was used to acquire data from the capacitive displacement probes at a fixed sampling rate of $1 \mathrm{MHz}$. This system and its application software were delivered as part of the SBIR contract for the capacitive blade-tip-clearance sensors. The system used custom data acquisition and processing applications that were tailored for acquiring and processing data from the capacitive sensors.

\section{Experimental Theory and Setup}

The theory behind the crack-detection methodology that was investigated was based on previous theoretical and experimental work performed by Abdul-Aziz et al., (Refs. 2 and 3), Gyekenyesi et al., (Refs. 7 and 8), and Haase and Drumm, (Ref. 9). The goal of this experiment was to determine if the crack-detection methodology investigated in these earlier studies could be validated by using the spin rig to conduct tests on simulated engine rotor disks with a notch introduced to replicate a crack.

The detection methodology is based on monitoring the vibration response of rotating disks to determine if a crack has developed. The theory implies that a defect, such as a crack, creates minute deformations in the disk as it is rotated. The deformation, in turn, creates a speed-dependent shift in the disk's center of mass. It was theorized that this shift could be detected by analyzing the amplitude and phase of the vibration (whirl) response as measured by the tip clearance profile. The system's behavior was modeled after a 2-degree-of-freedom Jeffcott rotor. The model predicts that the vibration amplitude peaks when a clean, undamaged disk goes through the first critical speed, but heads to a lower steadystate value as the speed is increased above the critical speed. Correspondingly, the phase shifts $180^{\circ}$ when going through the first critical speed and then stabilizes to a steady-state value as the speed is increased past critical. At this point, the rotor is rotating about the combined system's center of mass and has stabilized. However, as the speed of a cracked disk is increased, centrifugal forces open the crack. This, in turn, deforms the disk and shifts its center of mass. At speeds above critical, the crack-induced shift in the disk's center of mass starts to grow and dominate the overall system's vibration response. The modeling 


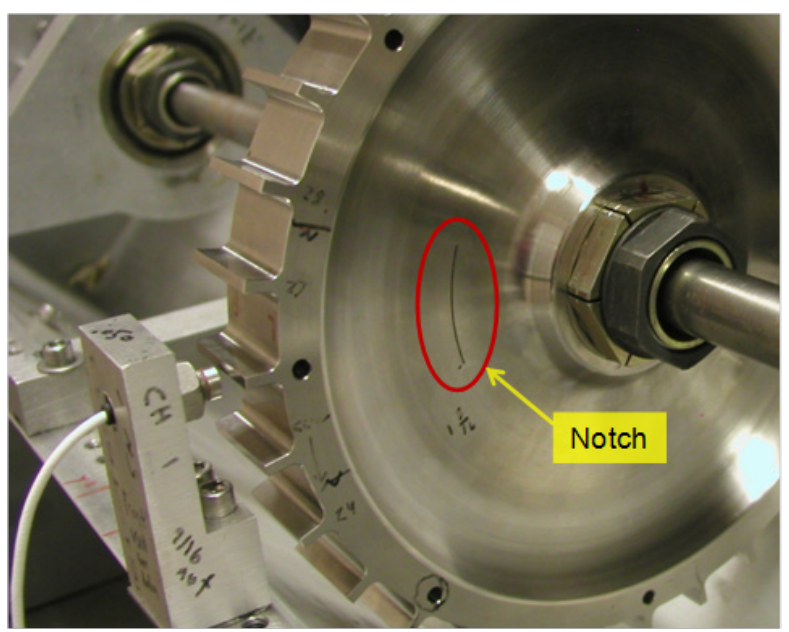

Figure 3.-Subscale turbine engine disk with notch.

predicts that, instead of heading toward a steady-state value, the vibration amplitude will change as a second-order function of rotational speed as it is increased beyond the first critical speed. This can be detected by analyzing the vibration response of the disk-rotor system, particularly the amplitude and phase of the first harmonic, as the system is operated over a range of speeds. The testing approach used in this experiment was to spin a simulated engine disk over a speed range from 0 to $12000 \mathrm{rpm}$ and simultaneously record its vibration response. The vibration response was acquired as previously described using capacitive displacement probes to measure the blade tip clearance profile. Two subscale simulated engine turbine disks were tested. The first disk was undamaged and was used to acquire the baseline vibration response data. The disk had an outside diameter of $235 \mathrm{~mm}$ (9.25 in.), a bore thickness of $25.4 \mathrm{~mm}$ (1 in.), and an outside rim thickness of $31.75 \mathrm{~mm}(1.25 \mathrm{in}$.$) .$

The thinnest portion of the disk's web was $2.54 \mathrm{~mm}(0.10 \mathrm{in}$.). Thirty-two teeth to simulate blades were evenly spaced around the circumference of the disk. Each simulated blade had a cross section of $31.75 \mathrm{~mm}$ (1.25 in.) by $3.30 \mathrm{~mm}(0.13 \mathrm{in}$.) and a height of $8.38 \mathrm{~mm}(0.33 \mathrm{in}$.). The disk was made of a nickel base alloy, Haynes X-750 (Haynes International, Inc.) and had a weight of $4.88 \mathrm{~kg}(10.75 \mathrm{lb})$.

The second disk is shown in Figure 3. It was identical to the baseline disk with the exception that a $50.8 \mathrm{~mm}$ ( 2 in.) long notch had been introduced in its mid-span region to imitate a crack in the disk. The mid-span region was selected because prior finite-element analysis had shown that this area experienced high stress levels during operation. The data acquired from this disk were compared with the data from the undamaged baseline disk to determine if the simulated crack could be detected by analyzing the vibration response. Supportive analytical calculations were made using finite-element analysis to complement the experimental work and determine the expected radial growth of the disk. The finiteelement analysis predicted a radial growth on the order of $\sim 0.075 \mathrm{~mm}(\sim 0.003 \mathrm{in}$.) at the highest operating speed, $12000 \mathrm{rpm}$. This was within the detection limit of the blade-tip-clearance instrumentation. However, it should be noted that the major effect that was to be monitored was how the notch changed the combined center of mass of the disk-rotor system and its combined vibration amplitude and phase - not the radial blade tip growth of the disk.

\section{Experimental Results}

The experimentation consisted of operating the baseline and notched disks at several speed profiles and recording their vibration responses using the capacitive blade-tip-clearance sensors. The first harmonic component of the tip-clearance profile for each revolution was then analyzed to determine if the amplitude and phase exhibited the expected characteristics associated with the simulated crack in the disk. Approximately 15 test runs were conducted for each disk. A typical test run or cycle consisted of ramping up the disk's speed from $0 \mathrm{rpm}$ to a predefined maximum speed, remaining on condition for 0 to $60 \mathrm{~s}$, 


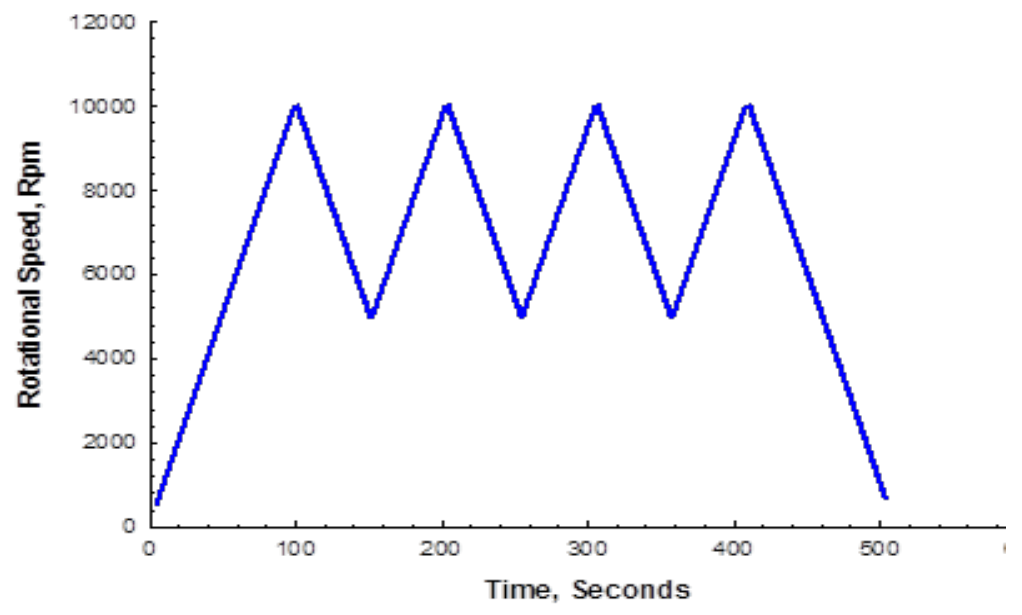

Figure 4.- Simulated mission profile.

then ramping back down to $0 \mathrm{rpm}$. Blade-tip-clearance data were acquired over the entire cycle. Data sets were acquired at ramp rates of 60 and $100 \mathrm{rpm} / \mathrm{s}$ for peak operating speeds of 5000, 10000 , and 12000 $\mathrm{rpm}$. In addition, complex mission profiles were conducted where the speed was ramped to various power levels in an attempt to simulate the rigorous loading conditions that an engine would experience during a typical mission.

The run profile presented in this paper is shown in Figure 4. It is typical of the profiles that were used in the investigation. For this test case, the speed of the disk was increased from 0 to $10000 \mathrm{rpm}$ at a ramp rate of $100 \mathrm{rpm} / \mathrm{s}$, cycled between 10000 and $5000 \mathrm{rpm}$ for three cycles, then ramped down from 10000 to $0 \mathrm{rpm}$. This was done to simulate a mission profile from cruise to full power and to observe the effects of cyclical loading on the disks.

Figure 5 shows the results from this multiple-cycle test run for both the baseline and notched disks. The figure shows the analysis for the last cycle, starting at $10000 \mathrm{rpm}$ and ending at $0 \mathrm{rpm}$. As previously discussed, the presence of a crack is indicated if a second-order speed-dependent variation can be observed in the vibration amplitude as it is operated in the post critical speed regime. In this test case, a speed-dependent rise was observed in the amplitude data for the notched disk. The area of interest showing the speed-dependent rise is highlighted within the circle of Figure 5(b). A curve-fit analysis, shown in Figure 6, was conducted on the vibration data in this region and it was found to closely follow a second-order polynomial fit. Thus, possibly indicating the presence of the notch or simulated crack. Even though the vibration data looked promising in this region, it was also observed that the second-order speed-dependent variation was not consistent over the entire range and that it appeared to reset itself at a speed of $\sim 9500 \mathrm{rpm}$. Moreover, this amplitude variation was not consistently observed in other test runs, which cast some doubt on whether the effect was entirely due to the notch or to some other factor that is yet to be determined. However, this case yielded the best data so far and showed positive indications of being able to detect a defect such as a crack by analyzing the disk's vibration response, specifically the vibration amplitude as a function of disk speed. It is theorized that what made this case different, and more promising than the other test runs, is that this test was conducted towards the end of a test series and that many cycles had been placed on the disk prior to this run. In addition, the disk experienced more loading because of the cyclical nature of the test profile. Overall, the results were promising and plans are in place to further investigate and develop this crack-detection technique as part of future studies. 


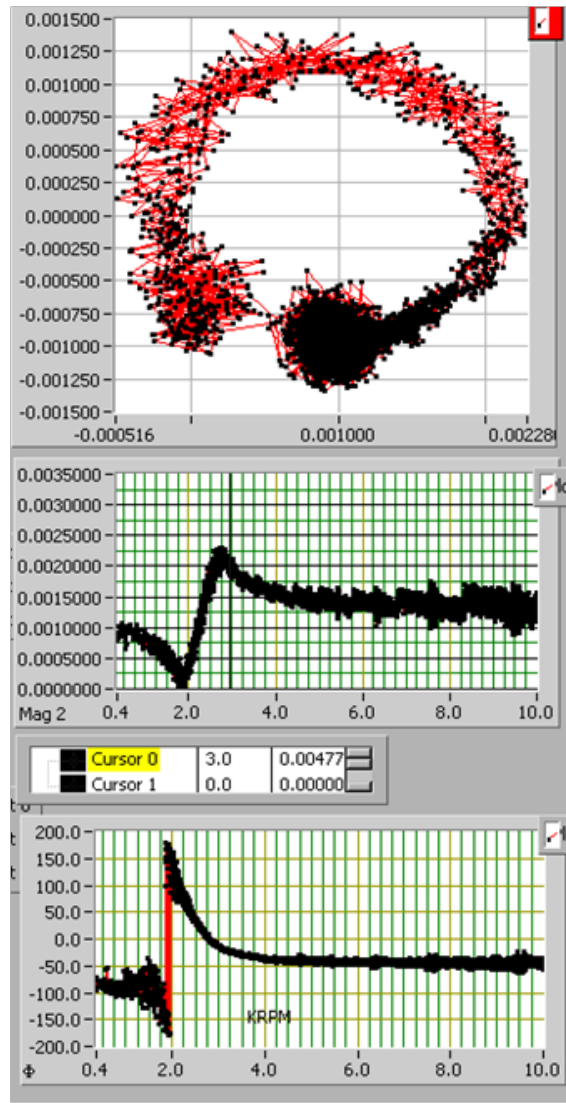

(a)

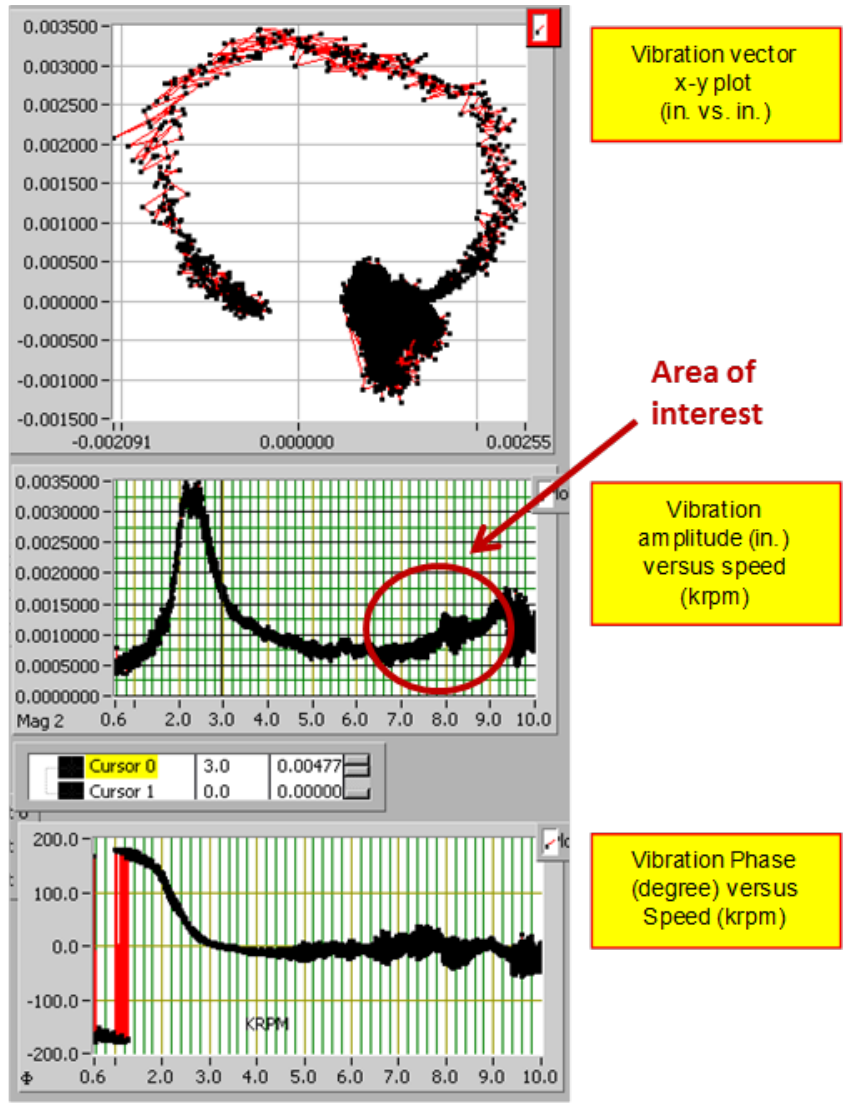

(b)

Figure 5.-10 000-rpm multiple-cycle run comparison. (a) Baseline disk. (b) Notched disk.

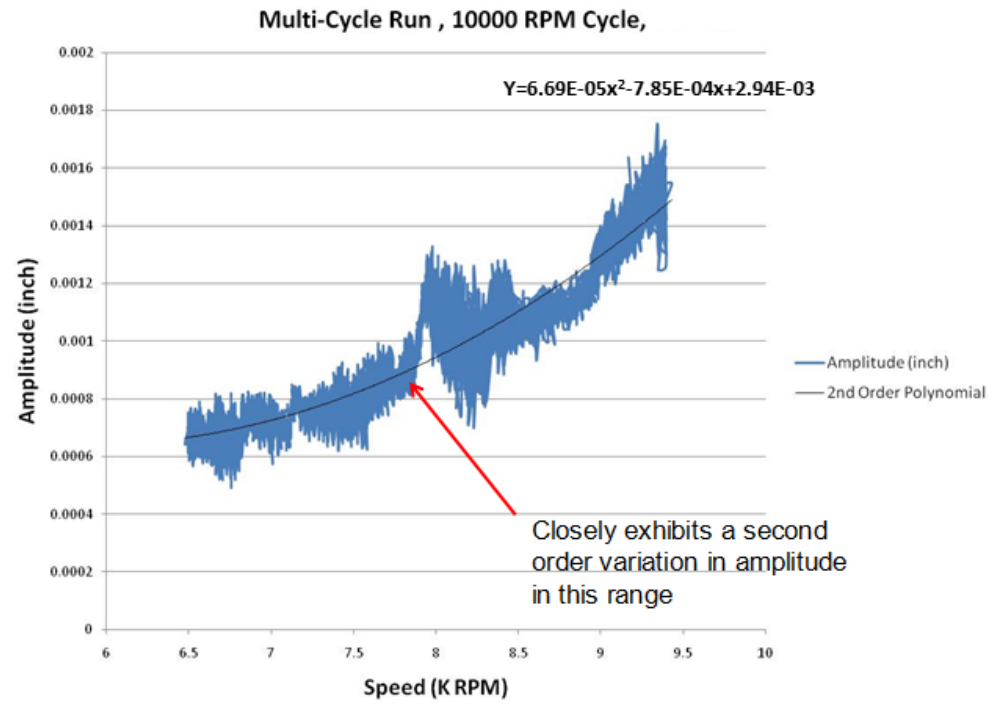

Figure 6.—Detailed vibration amplitude plot for 10 000-rpm multiple-cycle run. 


\section{Moiré Optical Based Crack Detection/Strain Measurement Technique}

The most recent investigation undertaken was to determine if an optical technique based on the Moire principal could be used to observe localized radial growth due to high stresses caused by an anomaly such as a crack in a rotating disk. This optical strain measurement technique is being developed in conjunction with NASA's Aeronautical Science Project-Innovative Measurements task. The experiment involved applying a circular reference pattern onto a subscale engine disk that had a notch machined into it to simulate a crack. The disk was operated at speeds up to $12000 \mathrm{rpm}$ as a means of optically monitoring the Moire created by the shift in patterns created by the radial growth of the disk due the presence of the simulated crack. In addition, displacement data sets were acquired using external blade tip clearance and shaft displacement sensors for comparison to the optical data. This investigation is a continuation of previous efforts undertaken in 2012 (Ref. 12) for the demonstration of this optical concept. The initial demonstration attempted on a subscale turbine engine disk and was inconclusive due to the lack of minimal detectable radial growth experienced by the disk during operation. For the present experiment a new subscale turbine engine disk was fabricated out of Aluminum and improvements were made to the experimental setup to better demonstrate the technique. Testing was first accomplished on a clean defect free disk as a means of acquiring baseline reference data. A notch was then machined on to the disk to simulate a crack and testing was repeated for the purposes of demonstrating the Moiré optical detection concept. The results from the previous investigation in 2012, and the partial results from the current baseline "clean" disk testing will be presented.

\section{Theory}

Moiré patterns are quite common in everyday occurrences and result from the overlap of figures with periodic spacing (Refs. 10 and 11). For this experiment it was desired to use the geometrical relationship associated with Moiré patterns as a means of optically measuring localized radial growth or strain in a rotating disk. The concept behind this technique is as follows.

Figure 7 shows the overlap of two vertical patterns. The first pattern has a vertical line spacing of $p$, while the second pattern has been "stretched" and has a vertical line spacing of $q$, which is related to $p$ by the following equation:

$$
\begin{aligned}
& q=p+\Delta p, \\
& 0<\Delta<1
\end{aligned}
$$

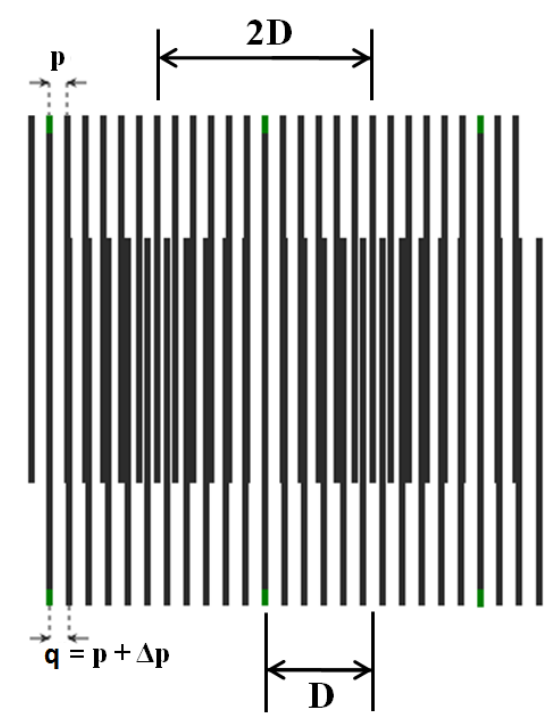

Figure 7.-Example of a Moiré pattern. 
If the patterns are lined up starting on the left side, the shift increases going to the right. Initially the lines of the patterns coincide and match up. This represents a light zone. After a given number of lines, the lines of the second pattern fall between the lines of the first. This represents a dark zone. This appearance alternates depending on whether the lines coincide (light zone) or are opposed (dark zone). The middle of the first dark zone is when shift in spacing between the first and second pattern is $p / 2$. The $n^{\text {th }}$ line of the second pattern is shifted by $n \cdot \Delta p$ when compared to the $n^{\text {th }}$ line of the first. Thus, at the middle of the first dark zone the following relationships can be established:

$$
\begin{gathered}
n \Delta p=\frac{p}{2} \\
n=p /(2 \Delta p)
\end{gathered}
$$

Where $n$ in Equation (3) is the number of lines on the second pattern that it takes to get to the middle of the dark zone. The distance, $D$, between the initial start point or the middle of a light zone, and the middle of the dark zone is then defined by the following:

$$
D=n(p+\Delta p)
$$

Substituting Equation (3) for $n$ at this point yields:

$$
D=\frac{p^{2}}{2 \Delta p}+\frac{p}{2}
$$

The distance between two dark zones or two light zones would be 2D. Finally, rearranging Equation (5) to solve for $\Delta p$ yields the following:

$$
\Delta p=\frac{p^{2}}{(2 D-p)}
$$

If the first pattern is as a baseline image of a test article in its initial state and the second pattern is obtained while the article is being loaded or stretched. Strain, $\varepsilon$, the test article is undergoing would be given by the following equations:

$$
\begin{gathered}
\varepsilon=\frac{\Delta p}{p} \\
\varepsilon=\frac{p}{(2 D-p)}
\end{gathered}
$$

Thus, by knowing the initial line spacing, $p$, and optically observing the distance between two dark zones or two light zones, 2D, or the distance between a light and dark zone, $D$, the difference in spacing, $\Delta p$, and hence strain, $\varepsilon$, can be calculated. 


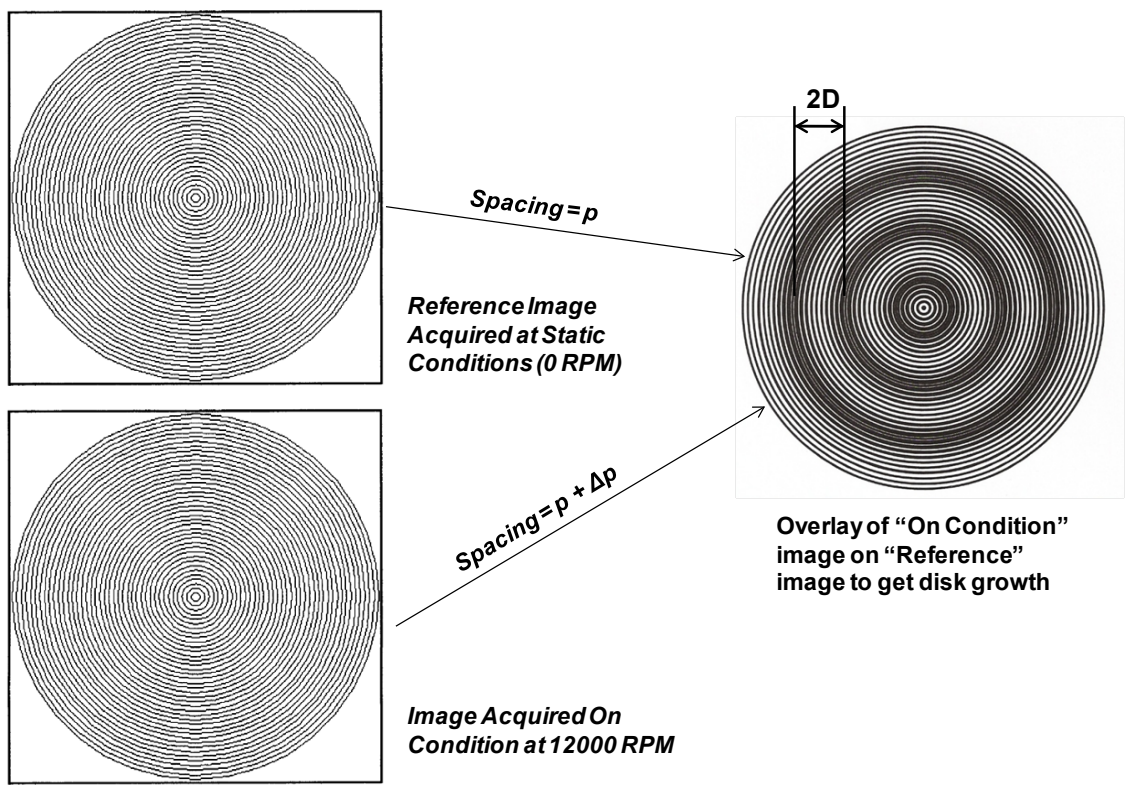

Figure 8.-Moiré concept applied to a rotating disk.

\section{Technical Approach}

The Moiré effect amplifies small changes and has the potential to make these changes optically measureable by observing the spacing between the dark or light zones of two patterns overlaid on each other. This characteristic is the basis of the experiment to measure radial growth or strain on a rotating disk due to high stresses caused by operation or an anomaly such as a crack. Figure 8 shows the overall concept behind the experiment. The technical approach was to apply a pattern of concentric equally spaced rings at a known spacing on a subscale turbine engine disk and acquire images of it at both static, $0 \mathrm{rpm}$, and at a loaded condition of $12000 \mathrm{rpm}$. The image that was taken on-condition was then overlaid on the static reference image using image processing software. Registration marks that were placed on the disk were used for sub-pixel alignment. The composite image was then analyzed for the appearance of the dark and light zones due to the radial growth of the disk. Measuring the distance between the dark zones, $2 \mathrm{D}$, or between a light and dark zone, $D$, and knowing the initial spacing, $p$, would allow the calculation of the strain and radial growth that the disk was subject to during operation. To enhance the localized stress that the disk would experience during operation, a $50.8 \mathrm{~mm}$ (2 in.) long notch was machined into it to simulate a crack.

\section{Experimental Setup Phase I Test Entry (2012)}

The subscale simulated turbine engine disk that was used in the initial experiment was the same disk that was used in the previously discussed Vibration Based Crack Detection experiments and is shown in Figure 9. The disk is $235 \mathrm{~mm}$ (9.25 in.) in diameter and has 32 evenly spaced teeth to simulate blades. Its geometry is representative of that encountered in turbine engine disks. The notch and image pattern that was machined onto the disk is also shown in Figure 9. The notch was machined into the disk prior to the experiment and was used for previous engine fault and crack detection experiments. The notch is located mid-span on the disk in the thinnest region. It is $50.8 \mathrm{~mm}(2.00 \mathrm{in}$.) long, $0.38 \mathrm{~mm}(0.15 \mathrm{in}$.) wide, and fully penetrates the disk with a depth of $2.54 \mathrm{~mm}(0.10 \mathrm{in}$.). The notch's purpose was to simulate a crack and enhance the localized stress and growth in the area around the crack. While considered large for realistic applications, it has served as an ideal test case in previous proof-of-concept fault and crack detection studies similar to the Moiré concept being investigated in this paper. The pattern that was applied to the disk in order to view the Moiré shift consisted of concentric circles that were $0.254 \mathrm{~mm}$ 


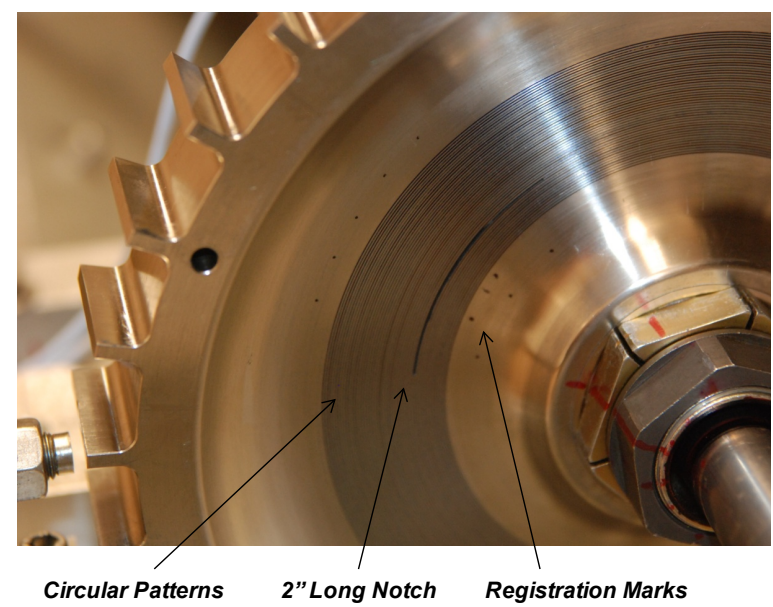

Figure 9.-Subscale engine disk with notch and pattern applied.

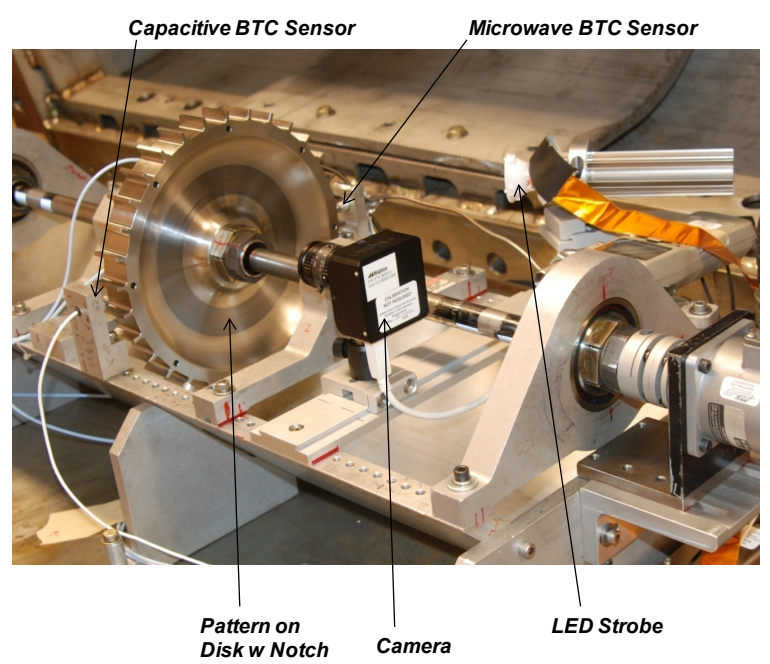

Figure 10.- Setup for Moiré crack detection experiment.

(0.010 in.) wide and uniformly spaced $0.508 \mathrm{~mm}(0.020 \mathrm{in}$.) apart. The pattern was machined on to the disk using a precision lathe. The circles were made just deep enough, $\sim 0.08 \mathrm{~mm}(\sim 3 \mathrm{mils})$, so that a material could be applied to the grooves to provide contrast when imaging. A blue dye used in machining applications was applied to the disk then lightly sanded off, leaving the dye in the grooves to provide the needed contrast for viewing the circular pattern. Registration marks were also added to the disk to facilitate the alignment of the images acquired statically and on-condition.

One issue that was encountered with the application of the patterns is that, due to the curvature of the disk's surface, only the flat portion of the disk from a radius beginning at $47.2 \mathrm{~mm}$ (1.86 in.) and ending at $71.6 \mathrm{~mm}$ (2.82 in.) was able to have the circles applied as opposed to covering the desired hub-to-blade region of the disk, which began at the shaft and ended at a radius of $\sim 109 \mathrm{~mm}$ (4.275 in.). It was also intended for the circle width and spacing to be on the order of $0.13 \mathrm{~mm}(0.005 \mathrm{in}$.). However, this was not able to be done in a consistent manner using the precision machining method that was employed, and resulted in the use of the larger $0.254 \mathrm{~mm}(0.010 \mathrm{in}$.) width and $0.508 \mathrm{~mm}(0.020 \mathrm{in}$.) spacing for the experiment. Both of these issues combined, limited the ability to observe the Moire dark and light zones set up in the pattern. Even with these limitations, it was decided to still proceed with the experiment to determine what could be observed and use it as a learning opportunity for further refining this technique for future use.

As was done for the vibration based crack detection experiment, the NASA Glenn Research Center's High Precision Spin Rig was used to operate the disk for this investigation. The setup for the experiment is shown in Figure 10. A five (5) Megapixel miniature machine vision digital camera with a $12 \mathrm{~mm}$ and 25 lens was used to acquire images of the disk statically and when it was being operated at $12000 \mathrm{rpm}$. To capture the image of the disk as it was being spun a $10 \mathrm{~W}$ white light emitting diode (LED) with pulsed power supply was used as a strobe. A laser $1 /$ rev was used to precisely drive the strobe as a function of rotor location and speed. In-house designed and fabricated pulse delay and pulse width control circuitry was used to condition the $1 /$ rev signal for control of the strobe. The pulse delay was varied in order to image different regions of the disk while it was spinning. The pulse width was adjusted to obtain the crispest image of the disk while it was on test condition. In addition to the optical instrumentation listed above, microwave and capacitive blade tip clearance (BTC) sensors were used to acquire blade tip clearance data. These sensors, shown in Figure 10, were located $180^{\circ}$ across from each other on the disk. The purpose of using this additional instrumentation was to compare any radial growth observed optically using the Moiré principle with the radial growth measured by these external sensors. 


\section{Experimental Results Phase I Test Entry (2012)}

\section{Optical Data}

As previously stated the methodology that was used to conduct the experiment was to acquire reference images of the disk at various locations at the static, $0 \mathrm{rpm}$ condition, then spin the disk up to $12000 \mathrm{rpm}$ and acquire images of the disk at full speed operation in the same the locations that the reference images were acquired at. The two locations that were chosen were the region located by the notch and a clean, defect free region, located $180^{\circ}$ across from it. These were chosen as a means of viewing the radial growth associated with normal loading of the disk and the localized radial growth due to the simulated crack. The images were then post processed by first aligning them using the registration marks located on the inside radius of the disk and then overlaying the image that was acquired at $12000 \mathrm{rpm}$ onto the image that was taken statically. Imaging processing software was used to accomplish the sub-pixel alignment and overlay of the images. The composite image was then analyzed for the appearance of the Moiré light and dark zones due to the radial growth of the disk.

Figure 11 shows the images that were acquired for the clean, or baseline region, of the disk using a $12 \mathrm{~mm}$ lens. Figure 11(a) shows the reference image acquired at static conditions, Figure 11(b) shows the on-condition image acquired at $12000 \mathrm{rpm}$ and Figure 11(c) shows the resulting composite image obtained by overlaying the two images. For the baseline region of the disk the two images lined up exactly on top of each other and the light and dark zones due to the Moiré shift were not observed. Thus, indicating that very little radial growth was observed during high speed operation, which was expected for this side of the disk.

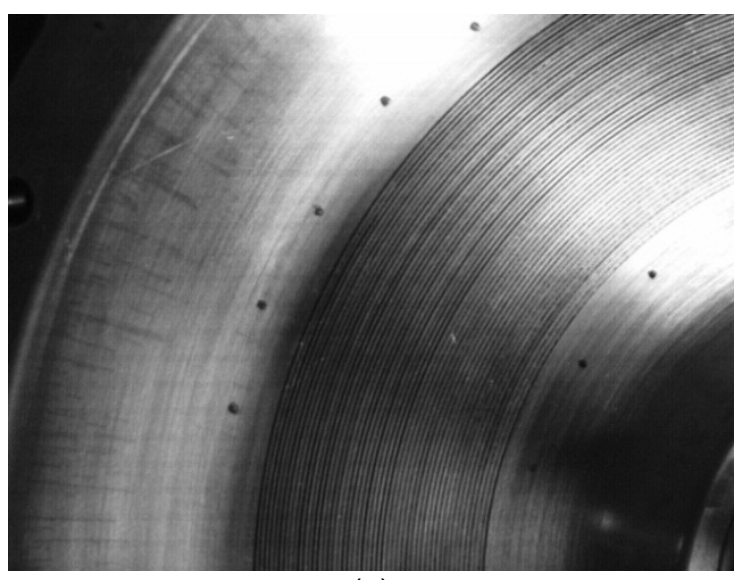

(a)

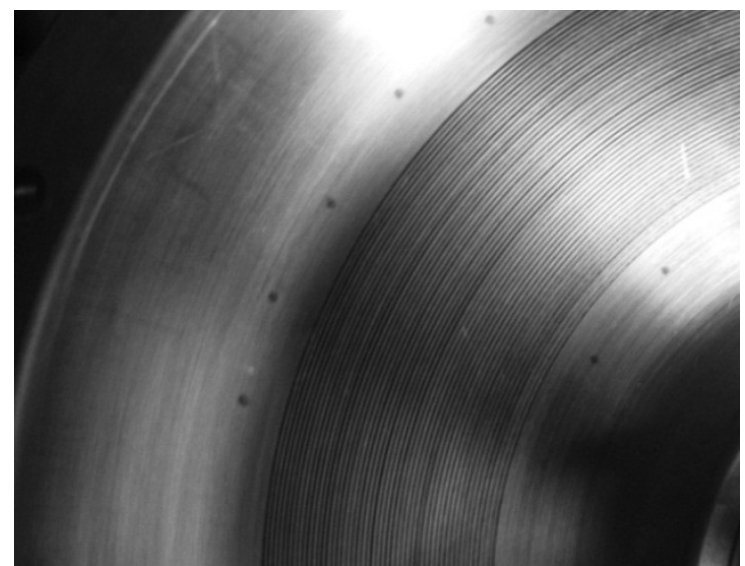

(b)

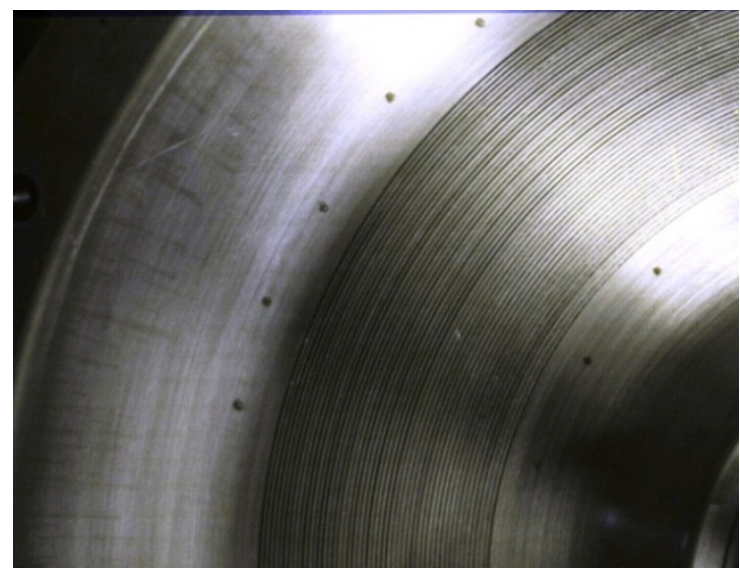

(c)

Figure 11.-Baseline region. (a) Static reference image. (b) On-condition image acquired at $12000 \mathrm{rpm}$.

(c) Composite image. 
Figure 12 shows the resulting composite image obtained by overlaying the on-condition and reference images that were acquired for the region of the disk where the notched was located. A $25 \mathrm{~mm}$ lens was used to magnify the region of interest. Again, as previously observed, the anticipated light and dark zones due to the Moiré shift were not observed. The static reference image patterns lined up almost perfectly on the patterns of the image taken at $12000 \mathrm{rpm}$. Thus, further verifying that the disk was experiencing very little if any growth due to the notch and the loads induced on it during operation. It should be noted that the same results were also observed when using the $12 \mathrm{~mm}$ lens on this area of the disk. This was unexpected, as finite element analysis showed that up to a $\sim 0.075 \mathrm{~mm}(\sim 0.003 \mathrm{in}$.) localized radial growth of the disk could be observed in the region of the notch under these loading conditions. The expectation was that at least the initiation of a pattern shift would be observable, especially in the rings beginning at the notch region and heading towards the outside edge of the disk. To further verify the lack of radial growth a line intensity profile analysis was conducted over the last 10 rings on the composite image to determine if there was a shift due to radial growth of the disk as this would represent the best region to detect any growth.

The region that was used for the intensity profile is indicated by the yellow line in Figure 12. The intensity profile is shown in Figure 13. The green line indicates the intensity for the image that was acquired at $12000 \mathrm{rpm}$ and the blue line indicates the intensity of the static reference image. The valleys on the chart indicate the location of the grooves or dark lines of the pattern. The peaks indicate the space between the grooves or the light lines of the pattern. From visually analyzing the profile it is evident that the peaks and valleys of the intensity profiles match each other in the $\mathrm{x}$-axis or radial direction on the disk. Again, this verifies that the disk experienced very little if any radial growth during operation, or that the growth is under the detection limits using this optical technique.

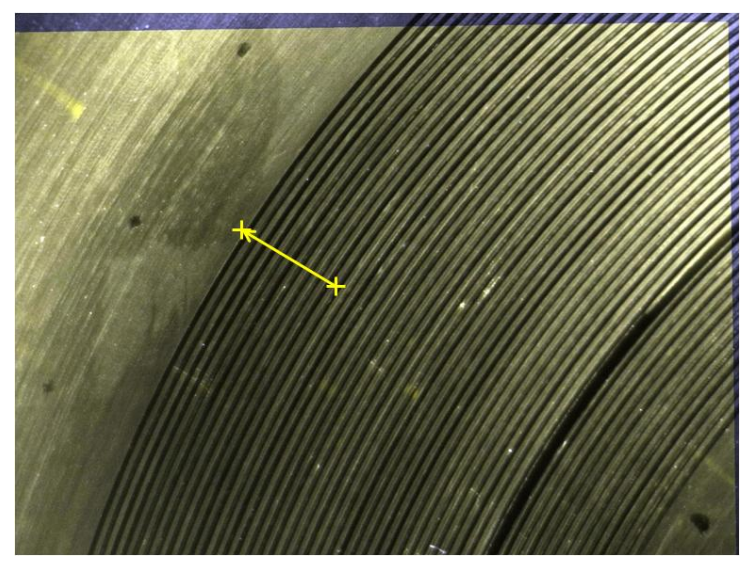

Figure 12.-Composite image of notch region at 12000 rpm using $25 \mathrm{~mm}$ lens.

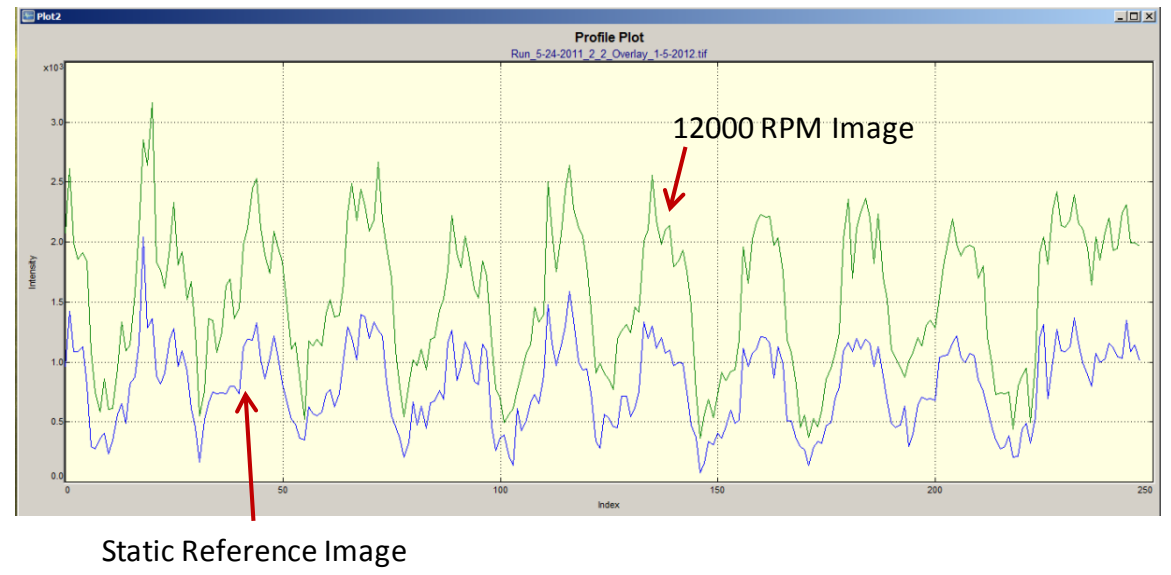

Figure 13.--Intensity profile. 


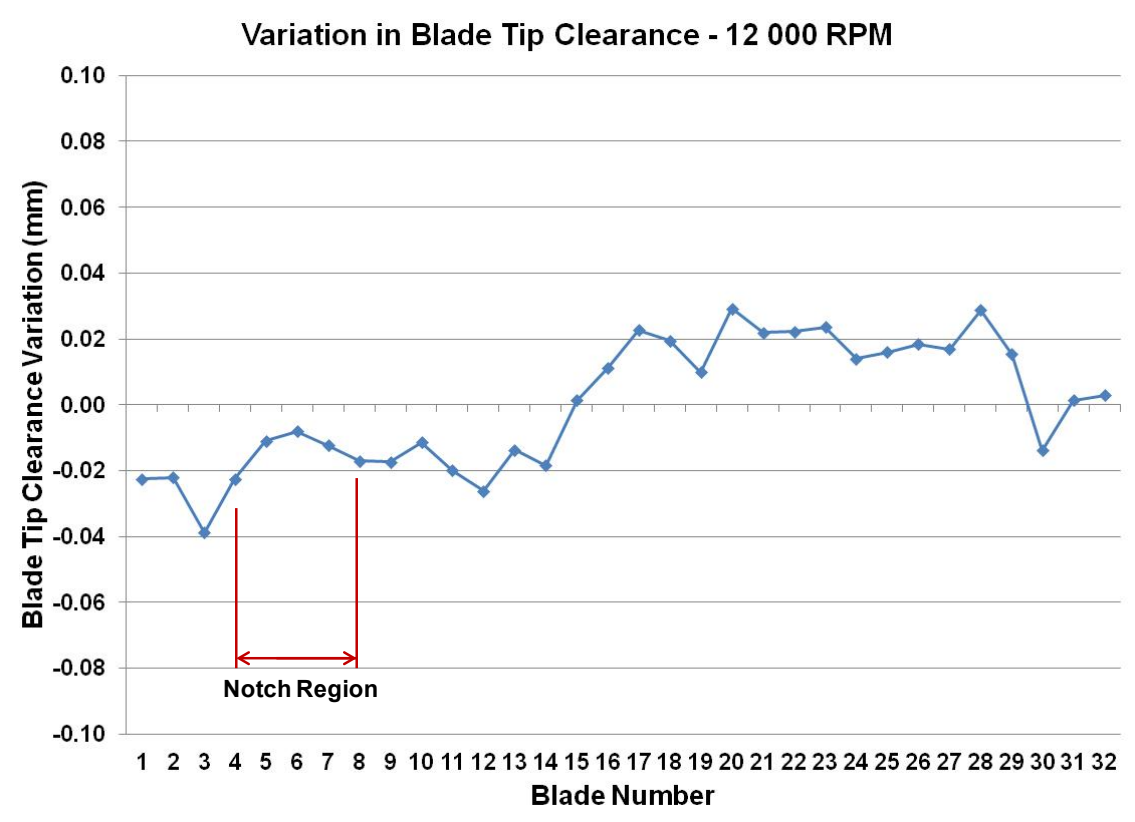

Figure 14.-Blade tip clearance profile.

\section{Sensor Data}

As part of this experiment displacement data sets were acquired using external blade tip clearance and shaft displacement sensors for comparison to the data obtained from the optical technique. Both microwave and capacitive based blade tip clearance sensors were used to measure the radial clearance for each blade and hence the radial growth of the disk. The variation in blade tip clearance as measured by the microwave blade tip clearance sensor over 1 revolution, 32 blades, at a rotational speed of $12000 \mathrm{rpm}$ is shown in Figure 14. The red line indicates the region of the disk that contains the notch. From analyzing the graph a variation of $+0.03 \mathrm{~mm}(+0.001 \mathrm{in}$.) to $-0.04 \mathrm{~mm}(-0.0016 \mathrm{in}$.) is observed during operation of the disk. This variation observed is due to the whirl amplitude caused from Rotordynamics of the diskrotor system rather than radial growth of the disk. A shaft whirl amplitude on the order of $\pm 0.03 \mathrm{~mm}$ (0.001 in.) has been measured and observed at $12000 \mathrm{rpm}$ on the eddy current shaft displacement sensors. In addition, in the area of the notch, the blade tip clearance is observed to be stable or actual slightly increasing, which is counter to what would be expected if the disk experienced localized growth in this region. Hence, the external sensor data verified what was observed on the optical data regarding the minimal blade tip radial growth on the disk during this experiment.

\section{Experimental Setup Phase II Test Entry (2013)}

Since the previous experiment was inconclusive due to the minimal radial growth experienced in the Haynes X-750 disk, several improvements were attempted for the continued investigation of this technique in 2013. First, a new simplified subscale disk was fabricated out of Aluminum (Fig. 15). This disk was made of a simple flat geometry which would better allow for the application of the circular Moiré pattern over the entire surface of the disk. This disk was $12.7 \mathrm{~mm}(0.50 \mathrm{in}$.) thick, $235 \mathrm{~mm}$ (9.25 in.) in diameter and had 32 evenly spaced teeth to simulate blades, each $12.7 \mathrm{~mm}(0.50 \mathrm{in}$.) long and $3.18 \mathrm{~mm}$ (0.125 in.) thick. Aluminum was chosen because it properties would allow for greater radial growth at the test conditions that it would be operated at. Thus, allowing for a better demonstration of this novel measurement concept. As in the previous experiment a notch was machined into the disk. The notch was located mid-span on the disk. It was $50.8 \mathrm{~mm}$ (2.00 in.) long, $0.30 \mathrm{~mm}(0.015 \mathrm{in}$.) wide, and fully penetrates the disk with a depth of $12.7 \mathrm{~mm}(0.50 \mathrm{in}$.). Again, the notch's purpose was to simulate a crack and enhance the localized stress and growth in the area around the crack. The second improvement that 


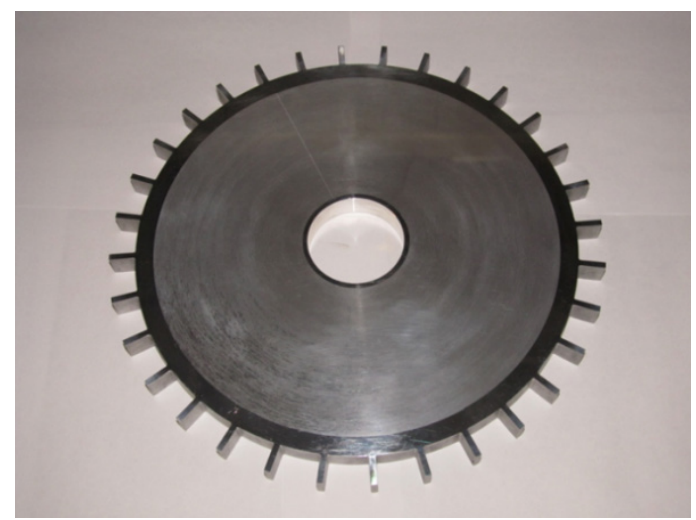

Figure 15.-Aluminum rotor disk with laser etched circular pattern.

was attempted was to apply the circular pattern to the disk using a laser etching process. This process yielded concentric circles that were $0.127 \mathrm{~mm}(0.005 \mathrm{in}$.) wide and uniformly spaced $0.254 \mathrm{~mm}$ (0.010 in.) apart. This was one half of the previous width and spacing achieved using the precision lathe application technique, thus doubling the pattern's measurement sensitivity. The pattern was able to be nearly applied nearly over the entire surface of the disk, starting at a radius of $24.9 \mathrm{~mm}(0.98 \mathrm{in}$.) and ending at a radius of $95.5 \mathrm{~mm}$ (3.76 in.). Registration marks were also added to the disk to facilitate the alignment of the images acquired statically and on-condition. The test setup in the High Precision Spin Rig was nearly identical to the setup discussed previously. The only difference this time was the use of a different light source controller which would allow for pulse width as low as $1 \mu \mathrm{s}$, in order to capture crisper images of the disk while it was rotating.

\section{Experimental Results Phase II Test Entry (2013)}

\section{Baseline Optical Data}

For this test entry it was decided to first test on a clean disk without the notch installed in order toobtain baseline data for demonstrating both the optical strain measurement crack-detection technique and the previously described vibration based crack detection technique. As in the phase I test entry, reference images were first acquired at the static, $0 \mathrm{rpm}$ condition, then after the disk was spun up to $12000 \mathrm{rpm}$, images were acquired on condition at the same locations as the reference images.

Figure 16 shows the composite images that were acquired for the region where it is intended to locate the notch at. The composite images were made by overlaying the images acquired at $12000 \mathrm{rpm}$ over the reference images. Figure 16(a) shows the composite image acquired using the $25 \mathrm{~mm}$ lens, Figure 16(b) shows the same composite image zoomed in to focus on the outer rings of the disk. From analyzing these images, no apparent shift was observed. Which was expected on this baseline disk as minimal growth was expected on the clean disk as it was operated at $12000 \mathrm{rpm}$. This was confirmed by running a line intensity profile over the last 10 rings on the composite image as this area would yield the largest detectable radial growth. The region that was used for the intensity profile is indicated by the yellow line in Figure 16(b).

The intensity profile is shown in Figure 17. The green line indicates the intensity for the image that was acquired at $12000 \mathrm{rpm}$ and the blue line indicates the intensity of the static reference image. The valleys on the chart indicate the location of the dark lines of the pattern. The peaks indicate the light lines of the pattern. From analyzing the profile it is evident that the peaks and valleys of the intensity profiles match each other in the $\mathrm{x}$-axis or radial direction on the disk. Again, this verifies that the baseline, undamaged disk experienced very little if any radial growth during operation. Which again was expected as the purpose of this test was to get baseline data for comparison to the notched disk data. However, a decrease in average blade tip clearance on the order of $0.04 \mathrm{~mm}(0.0016 \mathrm{in}$.) was observed in the capacitive displacement sensor 
data during the time interval that the disk was operated at $12000 \mathrm{rpm}$. It is not known if this was real or due to some temperature related phenomena on the sensor. One possible explanation is that the Aluminum disk grew due to the rig's temperature increasing during operation. With a thermal expansion coefficient of $12.3 \mathrm{E}-6$ in./in. per ${ }^{\circ} \mathrm{F}$ for Aluminum this would translate to an increase in disk temperature of $36^{\circ} \mathrm{F}$. While not out of the realm of possibilities, as the rig's motor does heat up the rig environment when operated at $12000 \mathrm{rpm}$, it is unlikely that the disk heated up that much in the 8 min that it was operated at for the test run. In addition, the radial growth of $0.04 \mathrm{~mm}(0.0016 \mathrm{in}$.) should have also been detectable in the optical data as this translates to a 2 to 3 pixel shift, which would have been observable in the outer rings of the disks pattern. A more likely scenario is that the sensitivity of the capacitive was affected by the increase of rig temperature, causing the apparent shift in measurement. This discrepancy is in the process of being reviewed and addressed in the next phase of testing with the notched disk.

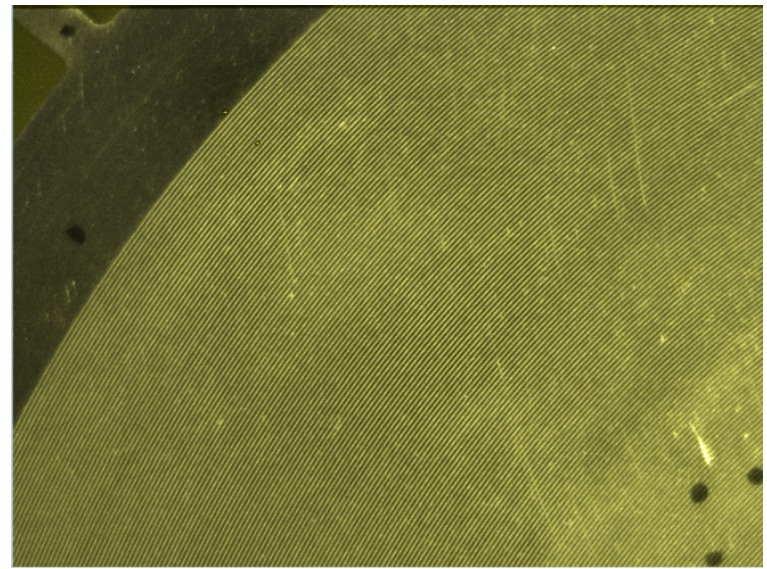

(a)

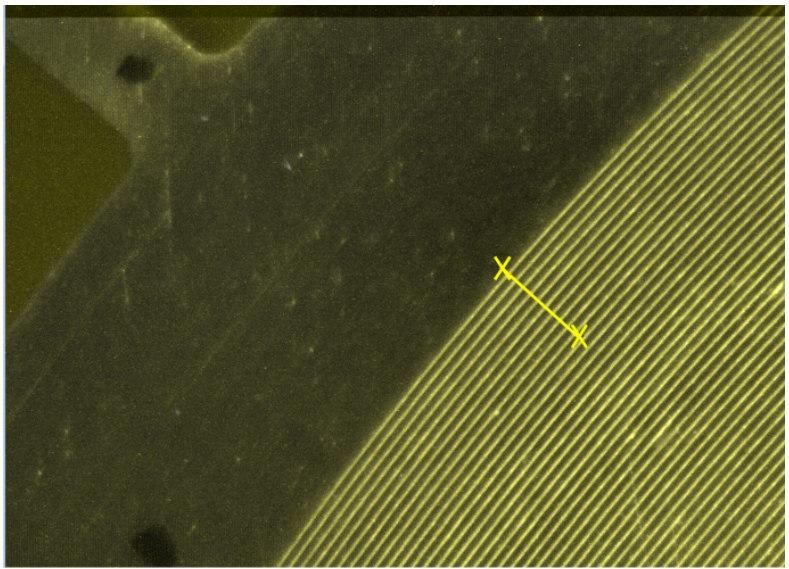

(b)

Figure 16.-Aluminum baseline disk at 12000 rpm. (a) Composite image. (b) Zoomed in to outer edge.

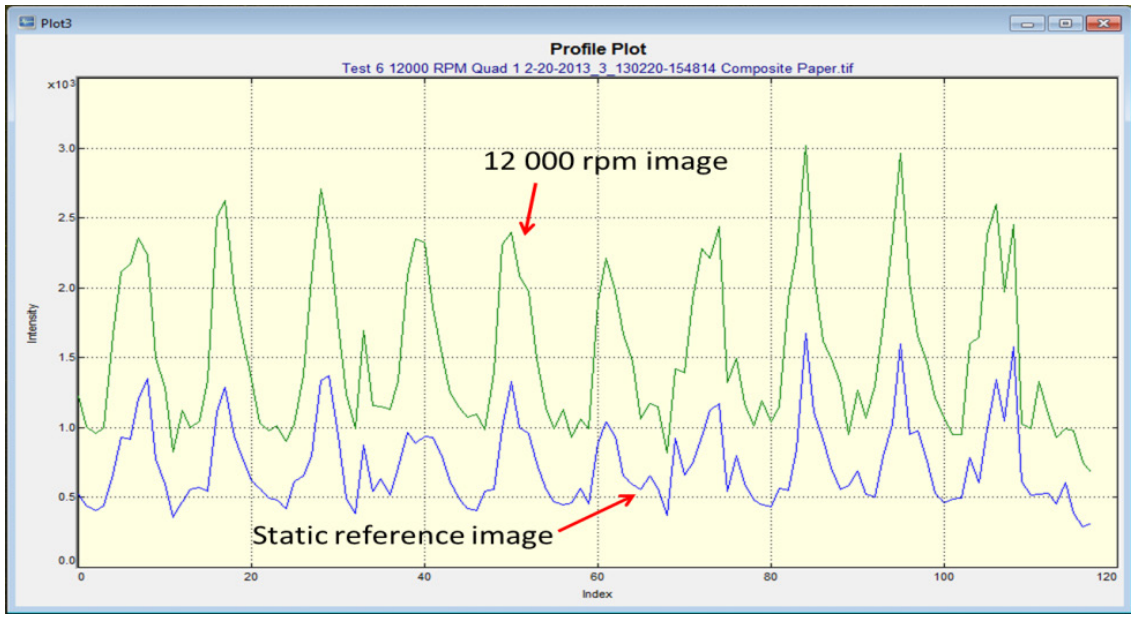

Figure 17.--Intensity profile Aluminum baseline disk. 


\section{Notched Disk Optical Data}

The disk with the notch is currently in the process of being tested and data was not yet ready to be presented at this time. It is planned to incorporate the additional of temperature monitoring to assess the increase in rig temperature and its effect on the blade tip clearance sensor readings and Aluminum rotor disk growth. In addition, a higher power lens and higher resolution camera will be used to maximize optical sensitivity. Current plans are to complete this testing and present the results as part of a future paper.

\section{Conclusion}

The results of two crack detection experiments were presented in this paper. The first experiment involved monitoring the vibration response on a disk as it was operated at speeds up to $12000 \mathrm{rpm}$. The vibration response was measured using externally mounted capacitive blade tip clearance sensors. Testing was performed on a clean undamaged baseline disk and a disk with a 50.8-mm- (2-in.-) long notch machined into the disk to simulate a crack. Test runs were conducted over several operational speeds to determine if a simulated crack could be detected by analyzing the combined disk-rotor system's vibration response (whirl amplitude and phase) as measured by the blade-tip-clearance sensors. The data acquired from the $10000 \mathrm{rpm}$ multiple-cycle test run yielded the best results. It showed a speed-dependent rise in the vibration amplitude, indicating that a crack-induced shift in the disk's center of mass was detectable at least for this particular test scenario. In the other test cases, it was noted that the system was on the verge of being able to detect the simulated crack using this technique, but not all of the expected trends were consistently observed. However, this technique does look promising and appears to have the sensitivity to detect cracks in a rotating disk. Additional investigations will be conducted in the future to further validate and refine this crack detection concept.

The second investigation was to determine if an optical technique based on the Moire principal could be used to measure localized radial growth and strain due to high stresses caused by an anomaly such as a crack in a rotating disk. The experiment involved etching a circular reference pattern on a subscale engine disk and introducing a $50.8 \mathrm{~mm}$ ( 2 in.) long notch machined into it to simulate a crack. The disk was operated at speeds up to $12000 \mathrm{rpm}$ and the Moiré pattern due to the shift with respect to the reference pattern was monitored as a means of detecting the localized radial growth of the disk due to the defect. The initial phase I investigation under taken in 2012 was found to be inconclusive as the test disk did not experience the radial growth that was expected in the notched area during operation. For the present phase II experiment (2013) a new subscale turbine engine was fabricated out of Aluminum and improvements were made to the pattern application to better demonstrate the technique. Testing was first accomplished on a clean defect free disk as a means of acquiring baseline reference data. This baseline data confirmed that the clean, undamaged disk experienced little or detectable radial growth as was predicted and expected by the finite element analysis model. A notch was then machined on to the disk to simulate a crack and testing was to be repeated for the purposes of demonstrating the technique. The optical data for the notched disk is currently in the process of being acquired and is not ready to be reported on at this time. However, this novel optical measurement technique does look promising and will continue to be investigated along with other optical techniques. In addition, displacement data that was acquired using blade tip clearance and shaft displacement sensors on the clean and notched disk during this test entry will be used to further validate the previously discussed vibration based crack detection technique. Plans are to report on these validation results and the optical data acquired on the notched disk in future papers. 


\section{References}

1. Woike, M.R., Abdul-Aziz, A., "Crack-Detection Experiments on Simulated Turbine Engine Disks in NASA Glenn Research Center's Rotordynamics Laboratory," NASA/TM-2010-216239, 2010.

2. Abdul-Aziz, A., Woike, M. R., Oza, N., Matthews, B. and Baaklini, G.Y., "Propulsion Health Monitoring of a Turbine Engine Disk Using Spin Test Data," NASA/TM-2010-216743, 2010.

3. Abdul-Aziz, A., Woike, M.R., Lekki, J.D., and Baaklini, G.Y., "Health Monitoring of a Rotating Disk Using a Combined Analytical-Experimental Approach," NASA/TM-2009-215675, 2009.

4. Abdul-Aziz, A., Woike, M.R., Lekki, J.D., and Baaklini, G.Y., "NDE Using Sensor Based Approach to Propulsion Health Monitoring of a Turbine Engine Disk," SPIE's 16th Annual International Symposium on Nondestructive Evaluation for Health Monitoring and Diagnostics, San Diego, CA, Mar. 9-12, 2009.

5. Abdul-Aziz, A., Trudell, J.J., and Baaklini, G.Y., "Finite Element Design Study of a Bladed, Flat Rotating Disk to Simulate Cracking in a Typical Turbine Disk; Part II," SPIE's 11th Annual International Symposium on Nondestructive Evaluation for Health Monitoring and Diagnostics, SPIE, San Diego, CA, Feb. 26-Mar. 2, 2006.

6. Abdul-Aziz, A., Trudell, J.J., and Baaklini, G.Y., "Finite Element Design Study of a Bladed, Flat Rotating Disk to Simulate Cracking in a Typical Turbine Disk," SPIE's 10th International Symposium on Nondestructive Evaluation for Health Monitoring and Diagnostics, San Diego, CA, Mar. 6-10, 2005.

7. Gyekenyesi, A.L., Sawicki, J.T., and Baaklini, G.Y., "Vibration Based Crack Detection in a Rotating Disk, Part 1—An Analytical Study," NASA/TM-2003-212624, 2003.

8. Gyekenyesi, A.L., Sawicki, J.T., Martin, R.E., Haase, W.C., and Baaklini, G.Y., "Vibration Based Crack Detection in a Rotating Disk, Part 2-Experimental Results," NASA/TM-2005-212624/ PART2, 2005.

9. Haase, W., and Drumm, M., "Detection, Discrimination and Real-Time Tracking of Cracks in Rotating Disks," IEEE 0-7803-7321-X/01, 2002.

10. Oster, G., Nishijima, Y., "Moire Patterns," Scientific American, p. 54-63, 1963.

11. http://switzernet.com/people/emin-gabrielyan/070306-optical-speedup/\# Toc160944479

12. Woike, M.R., Abdul-Aziz, A., Fralick, G., and Wrbanek, J., "Investigation of a Moiré Based Crack Detection Technique for Propulsion Health Monitoring," NASA/TM-2010-217622, 2012. 


